Sādhanā Vol. 40, Part 4, June 2015, pp. 1257-1272. (C) Indian Academy of Sciences

\title{
Shunt hybrid active power filter for harmonic mitigation: A practical design approach
}

\author{
UNNIKRISHNAN A K ${ }^{1, *}$, CHANDIRA SEKARAN E ${ }^{2}$, \\ SUBHASH JOSHI T $\mathrm{G}^{1}$, MANJU A $\mathrm{S}^{1}$ and ABY JOSEPH ${ }^{1}$ \\ ${ }^{1}$ Centre for Development of Advanced Computing (CDAC), Trivandrum 695033, India \\ ${ }^{2}$ Coimbatore Institute of Technology, Coimbatore 641014, Tamil Nadu, India \\ e-mail: unnikrishnan@ieee.org; subhashj@cdac.in; manjuas@cdac.in; \\ abypj@cdac.in; ecseeecit@gmail.com
}

MS received 9 June 2014; revised 13 October 2014; accepted 23 January 2015

\begin{abstract}
The increasing importance of Power Quality problems has been responsible for several improvements in Active Power Filter (APF) typologies in the last decade. The increased cost and switching losses make a pure shunt APF economically impractical for high power applications. In higher power levels shunt Hybrid Active Power Filter (HAPF) has been reported to be a useful approach to eliminate current harmonics caused by nonlinear loads. This paper presents a control strategy and design criteria for transformer-less shunt HAPF with special attention to the integration of series passive filter. The paper also compares the performance improvement of passive harmonic filter when modified as shunt HAPF. Experimental results obtained verify the viability and effectiveness of the proposed design criteria and control algorithm.
\end{abstract}

Keywords. Power quality (PQ); harmonic compensation; passive power filter (PPF); active power filter (APF); hybrid active power filter (HAPF); PWM converter.

\section{Introduction}

As technology advances, nonlinear loads are multiplying in numbers and the resulting complexity throws tremendous challenge to the quality of power supply. Because of the strict requirement of power quality at the input a.c. mains, various harmonic standards and engineering recommendations such as IEC 1000-3-2, IEEE 519 (USA), AS 2279, D.A.CH.CZ, EN 61000-3-2/EN 61000-3-12, and ER G5/4 (UK) are employed to limit the level of distortion at the PCC. To comply with these harmonic standards, installations utilizing power electronic and nonlinear loads often use one of the growing numbers of harmonic mitigation techniques (Hussein Kazem 2013).

*For correspondence 
Conventionally, the Passive Power Filter (PPF), consisting of a bank of tuned LC filters connected in shunt with the load, is used to solve the problems of harmonic pollution. At a tuned harmonic frequency, Shunt PPF exhibits lower impedance than the source impedance; hence, it bypasses major part of the harmonic currents to reduce the harmonic currents flowing into the source. In principle, filtering characteristics of the shunt PPF are determined by the impedance ratio of the source and the shunt PPF. This introduces strong influence of source impedance in its filtering characteristics. Other inherent problems, which discourage the use of PPF are that they cannot modify their compensation characteristics by following the dynamic changes of the nonlinear load harmonics spectrum and are also susceptible to sinking the harmonics injected by other loads in the grid. Also the probability of generating series resonances with the power system's equivalent reactance reduces power system stability. Another disadvantage of PPF is related to the small design tolerances acceptable in the values of $\mathrm{L}$ or $\mathrm{C}$, which can modify significantly the filter resonant frequency. For example, a 5\% difference in the selected value of $\mathrm{L}$ or $\mathrm{C}$ in a second-order filter, tuned at $250 \mathrm{~Hz}$ ( $5^{\text {th }}$ harmonics) modifies the designed resonant frequency by $7 \%$ with respect to the selected design value. This change in the value of the resonant frequency affects the filter current harmonic compensation performance. In particular, for industrial loads connected to stiff supply (low source impedance), it is difficult to achieve PPF with sharp tuning and high quality factor (Makram et al 1993), so that it diverts a significant part of the load harmonic current (Das 2004; Wu et al 1998). In summary since PPF is not a current controlled system, the amount and order of harmonics sinking/sourcing is uncontrollable. To overcome these shortcomings of PPF, various Active Power Filter (APF) configurations have been reported. At the same time, the following problems of shunt APF have been pointed out (Peng 1998; Akagi et al 2003). The Volt Ampere (VA) rating of the PWM converter in these APF becomes very large because they must withstand the line-frequency source voltage and supply the harmonic currents. Realizing such a large rated PWM converter with rapid current response with limited d.c. bus voltage is difficult. As an alternative to overcome the problems of PPF and pure APF, and inheriting the advantages of both, hybrid active power filters (HAPF) have been proposed (Akagi 1996). They are realized by combining both passive and active power filters. Two types of HAPF were proposed in 1988 (Akagi 1996) and in 1990 (Fujita \& Akagi 1991), respectively. Simplified circuit configurations of Series HAPF (Akagi 1996; Peng et al 1993) and Shunt HAPF (Rastogi et al 1995; Bhattacharya et al 1997) were established. In series HAPF, physical isolation for maintenance becomes difficult and it must handle full load currents. In shunt HAPF, APF is connected in series with PPF and the whole system is connected in parallel to the load. This is a more implementation friendly topology. It is shown that shunt HAPF does not require any transformer for connecting even up to $6.6 \mathrm{kV}$ grid (Inzunza \& Akagi 2005).

The control algorithms of APF are in continuous development (Uyyuru et al 2009). The first one was proposed on the basis of the Instantaneous Reactive Power Theory (Herrera et al 2008; Akagi et al 1986); other ones are based on the Synchronous Reference Frame (Bhattacharya et al 1991); also some extensions of them have been developed (Komatsu \& Kawabata 1997; Soares et al 1997). Recently, ANN based Predictive and Adaptive controller is proposed (Avik Bhattacharya \& Chandan Chakraborty 2011).

The authors could not find a literature which gives the design methodology of shunt HAPF. This paper presents design criterion and control strategy for transformer-less shunt HAPF with special attention to the integration of series passive filter with the support of theoretical analysis. Experimental results also obtained to compare the performance of existing passive filter when reconfigured as shunt HAFP. The design criteria and control algorithm were validated on a 415 V, $50 \mathrm{~Hz}, 50 \mathrm{kVA}$ laboratory system. 


\section{Shunt hybrid active power filter implementation}

\subsection{Working principle}

The shunt HAPF topology used in this paper, shown in figure 1, is implemented with a threephase PWM voltage-source converter connected in series to the passive filter built using inductor, $L_{f}$, and capacitor, $C_{f}$. The filter capacitor, $C_{f}$, is designed to offer high impedance to the line frequency and drops most of the grid voltage across it. Hence effectively no or negligible fundamental voltage appears across the a.c. terminals of the APF used in the shunt HAPF. This reduces the d.c. voltage requirement to a much lower level and allows it to connect to grid directly without transformer. This in turn reduces the VA rating of APF and makes shunt HAPF topology suitable for high power applications. It may be noted that since grid voltage appears across the LC filter, it will force a fundamental reactive current to flow into it.

To compensate the harmonics present in the grid current the scheme will force all the harmonic currents present in the load current to flow into shunt HAPF, whereas it restricts the sinking of other harmonic currents present in the grid. This improves the filtering performance of the passive filter, and prevent from overloading. Moreover, compensation characteristics of already installed PPF can also be significantly improved by connecting an APF in series with PPF, giving more flexibility and adding insensitivity to grid parameter variations.

\section{(a) Starting procedure}

Following are the practical operational sequence of the Shunt HAPF (SHAPF).

Figure 1 shows the one line diagram of the SHAPF connected to a distribution feeder. $T_{1}$ is a distribution transformer and the non-linear load is represented by a diode bridge connected to a d.c. capacitor $C$ and load resistor $R$. SHAPF consists of an L-C series filter $L_{f}, C_{f}$ tuned for a dominant lower harmonics frequency, connected to the 3 phase IGBT based PWM converter through a combination of contactor, Resistor $R_{1}$ and solid state relay SSR.

Before starting SHAPF, a.c. capacitor, $C_{f}$, should be pre-charged to prevent over-currents during startup. After powering the control supply the start action is initiated. Now, the three

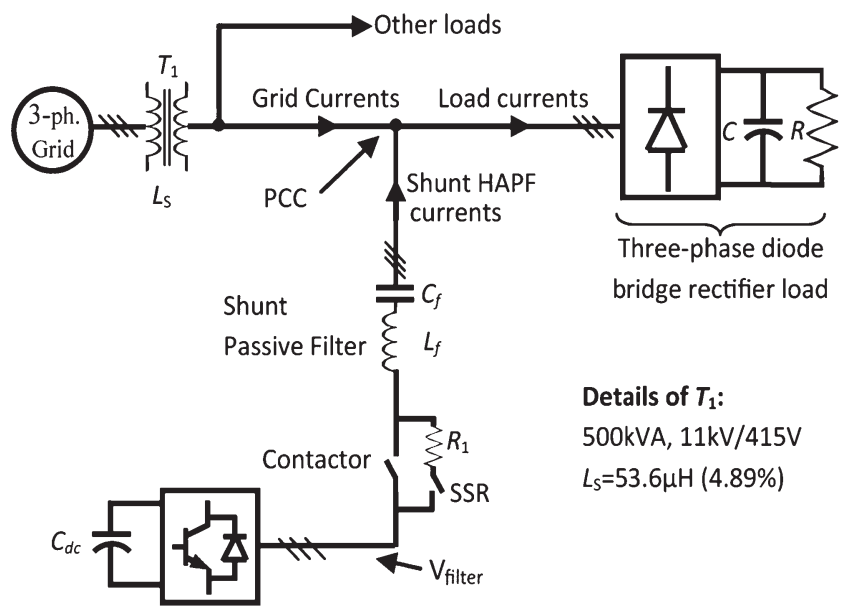

Figure 1. Shunt hybrid active power filter. 
upper IGBTs of the converter are turned on while the bottom three IGBTs are turned off. Then the $S S R$ will be made on bringing the resistance, $R_{1}$ of value $50 \Omega$, into the power circuit, forming wye-connected LCR filter. The resistor $R_{1}$ prevents over-currents from flowing into the shunt HAPF at startup. After a time of $400 \mathrm{~ms}$, the contactor will be turned on, bypassing the resistor. After this, the PWM signal will be provided to IGBTs based on the modulating signals generated by controller.

\subsection{Design procedure}

The criteria used for the design of major components present in the shunt HAPF are described below.

(a) Selection of resonant frequency $\left(f_{r}\right)$ of the LC filter

The resonant frequency of passive LC filter present in the shunt HAPF is given by,

$$
f_{r}=\frac{1}{2 \pi \sqrt{L_{f} C_{f}}}
$$

Sensibly the resonant frequency should be selected close to the predominant load current harmonic frequency which needs to be compensated. Since the passive filter selected is a single tuned filter, while selecting the resonant frequency, the focus should be to minimize the impedance offered to the load current harmonics that are being compensated. In this work the load harmonics considered for compensation are $5^{\text {th }}, 7^{\text {th }}, 11^{\text {th }}$ and $13^{\text {th }}$ order. Hence the resonant frequency is chosen as $7^{\text {th }}$ harmonic order, since it offers less impedance to the $11^{\text {th }}$ and $13^{\text {th }}$ harmonic components, compared to that tuned for $5^{\text {th }}$ harmonic frequency. Hence, if $f$ is nominal grid frequency,

$$
\frac{f_{r}}{f}=7
$$

(b) Design of filter inductor, $\mathrm{L}_{f}$ and filter capacitor, $\mathrm{C}_{f}$

The selection of inductance, $L_{f}$, and capacitance, $C_{f}$, has many criteria that should be considered simultaneously. The PPF should have minimum impedance at the frequencies of harmonic that are being compensated, such as $5^{\text {th }}, 7^{\text {th }}, 11^{\text {th }}$ and $13^{\text {th }}$, which can be achieved by increasing bandwidth by reducing the characteristic impedance given by,

$$
Z=\sqrt{L_{f} / C_{f}}
$$

Characteristic impedance, from (3), can be reduced by increasing $C_{f}$ and reducing $L_{f}$. But large value of $C_{f}$ will introduce a large capacitive reactive current to flow through the shunt HAPF, which will have more impact on source p.f. and increase the current rating. On the other hand, reducing the value of $L_{f}$ increases the switching ripple in the shunt HAPF current. Hence, selection of $L_{f}$ and $C_{f}$ is a trade-off between various conditions, which is represented in inequalities detailed below:

(i) The upper limit of the filter capacitor value is fixed such that capacitive reactive current drawn by it is only $10 \%$ of the rated load current. In such condition, even if the load feeder p.f. is 
unity the grid is degraded only by $0.5 \%$, whereas for lagging load p.f. it will improve the situation. If the resistance of passive filter and the relatively small fundamental pole voltage of converter are neglected, this capacitive reactive current is given by

$$
I_{\text {conv }(\text { fund })}=\frac{V_{\text {grid }}}{\left|\left(2 \pi f L_{f}-\frac{1}{2 \pi f C_{f}}\right)\right|} \leq 0.1 I_{L}
$$

where $V_{\text {grid }}$ is the rated phase to neutral grid voltage, $f$ is the nominal grid frequency and $I_{L}$ is the rated load current.

Rewriting (4) by applying (1) and (2),

$$
L_{f} \geq \frac{V_{\text {grid }}}{9.6 \pi f I_{L}}
$$

(ii) Choosing a smaller value of $L_{f}$ increases the switching voltage ripple at Point of Common Coupling (PCC). By considering high frequency equivalent circuit of figure 1, the source inductance $L_{S}$ and passive filter inductance $L_{f}$ will form a voltage divider circuit at the switching frequency. Hence, the ratio of switching ripple voltage at PCC to the active power filter terminal is given by,

$$
\frac{V_{s w(P C C)}}{V_{s w(A P F)}} \approx \frac{L_{s}}{L_{s}+L_{f}}
$$

where $L_{s}$ is the source inductance, which is equal to the leakage inductance of transformer $\mathrm{T}_{1}$ shown in figure 1. Limiting the maximum switching ripple appearing at PCC voltage due to APF voltage to $10 \%$, (6) can be rewritten as,

$$
L_{f} \geq 9 L_{s}
$$

(iii) Consider a half switching cycle. It can be shown from the Space vector PWM generation technique, that when the magnitude of B-phase modulating signal is highest among the three phases and that of Y-phase is lowest, R-phase terminal switches between 0 and $\pm \mathrm{V}_{\mathrm{dc}} / 3$, with respect to the fictitious neutral point. Since, maximum peak to peak ripple in the active filter current occurs when switches are in the active vector stage and duty ratio is $50 \%$,

$$
\Delta i_{p k-p k}=\frac{V_{d c}}{3} \frac{T_{o n}}{L_{f}}=\frac{V_{d c}}{3} \frac{T_{s} / 2}{L_{f}}=\frac{V_{d c}}{6 L_{f} f_{s}}
$$

where $V_{d c}$ is the d.c. voltage, $T_{o n}$ is ON time of the switch, $T_{s}$ is the switching period and $f_{s}$ is the switching frequency of active power filter.

Limiting the maximum peak to peak ripple to $15 \%$ of the rated active filter current, (8) can be rewritten as

$$
L_{f} \geq \frac{V_{d c}}{0.9 f_{s} I_{c o n v}}
$$

where $I_{\text {conv }}$ is the peak value of rated shunt HAPF current.

As discussed earlier, for better bandwidth of passive filter, $L_{f}$ should be minimised. The minimum value of $L_{f}$ is given by the minimum of (5), (7) and (9) which also give the upper limit of $C_{f}$. Once $L_{f}$ is fixed, $C_{f}$ can be calculated from (1). 
(c) d.c. voltage of shunt HAPF

Since the fundamental frequency grid voltage is dropped across $C_{f}$, the d.c. voltage is required only to inject the harmonic current required by the load, by the help of the converter. The harmonic voltage appearing across the passive filter when active power filter inject this current is given by,

$$
v_{\text {filter }}=R_{f} i_{\text {conv }}+L_{f} \frac{d i_{\text {conv }}}{d t}+\frac{1}{C_{f}} \int i_{\text {conv }} d t
$$

where $R_{f}$ is the equivalent resistance of the passive filter. Here the d.c. bus voltage is fixed as $300 \mathrm{~V}$ which is sufficient to generate harmonic voltage $v_{\text {filter }}$.

(d) d.c. bus capacitance, $\mathrm{C}_{d c}$, and its ripple current

If the internal losses in the shunt HAPF is neglected the power balance equation between d.c. and a.c. variable is given by,

$$
V_{d c} I_{d c}=V_{\text {Rgrid }} I_{R c o n v}+V_{Y g r i d} I_{Y c o n v}+V_{B g r i d} I_{B c o n v}
$$

where $V_{\text {Rgrid }}, V_{Y \text { grid }}$ and $V_{\text {Bgrid }}$ are the R-phase, Y-phase and B-phase grid voltages respectively, $I_{R c o n v}, I_{Y c o n v}$ and $I_{B c o n v}$ are the R-phase, Y-phase and B-phase shunt HAPF current respectively and $I_{d c}$ is the averaged d.c. current of shunt HAPF.

For a balanced system the average value of the d.c. current will result into zero. But due to switching action the instantaneous current through the capacitor is not zero and exact analytical method to derive d.c. current is complex in nature. An empirical formula derived for the r.m.s. value of ripple current in the d.c. capacitor, $C_{d c}$, shown in figure 1 , using simulation by taking various conditions is given by,

$$
I_{c(r m s)}=\frac{I_{c o n v}}{2}
$$

For the worst case design, considering the frequency of ripple current as $6^{\text {th }}$ harmonic, capacitance of the d.c. bus capacitor, $C_{d c}$, is given by,

$$
C_{d c}=\frac{I_{c(r m s)}}{3 \sqrt{2} \pi f \Delta V_{d c(p k-p k)}}
$$

where $\Delta V_{d c(p k-p k)}$ is the peak to peak ripple in the d.c. voltage.

\section{Control algorithm}

To mitigate the harmonics present in the grid currents, most of the APF's generate and supply the harmonics demanded by the non-linear loads at any instant. This is achieved by a control algorithm which carries out two basic functions as described below.

\subsection{Extraction of current reference}

Synchronous d-q reference frame (Bhattacharya et al 1991) based method is used for the extraction of load current harmonics. Unit vectors required for this method is constructed using the method explained in (Subhash Joshi et al 2003). Both shunt HAPF and load currents, shown in 
figure 1, are oriented along the grid voltage using the unit vectors. After orientation, on d-axis and q-axis, fundamental components become d.c. quantities, $5^{\text {th }}$ and $7^{\text {th }}$ order harmonics become $6^{\text {th }}$ order and so on. Load current harmonics can be extracted from the above by removing the d.c. quantities from the oriented load currents using a first order high pass filter (HPF). HPF can be easily implemented using low pass filter (LPF) as.

$$
H P F=1-L P F=1-\frac{\omega_{C}}{\left(s+\omega_{C}\right)}
$$

where $\omega_{\mathrm{c}}$ is the corner frequency of LPF.

The corner frequency $\left(\omega_{\mathrm{c}}\right)$ of LPF is selected to pass the d.c. and remove the a.c. components. The corner frequency is set as $5 \mathrm{~Hz}$, which is much less than the next harmonic, $600 \mathrm{~Hz}$.

By orienting the shunt HAPF current on d-axis and q-axis, the fundamental components are represented by d.c. quantities. Here, d-axis component represents active component of the current and q-axis component represents capacitive current drawn by the passive filter. Since grid voltage needs to be dropped across the passive filter, this capacitive reactive current should be left as it is by the current controller. To achieve this, the d.c. quantities on d-axis and q-axis are extracted using first order LPF of corner frequency $5 \mathrm{~Hz}$ and are added with d-axis and q-axis components of load current harmonics already obtained. This results into the total d-axis and q-axis current references.

\subsection{Shunt HAPF current and d.c. voltage controllers}

The current controller is implemented using PI-controller in $\alpha-\beta$ plane. Hence, the estimated total $\mathrm{d}$-axis and $\mathrm{q}$-axis current references are transformed to $\alpha-\beta$ plane using unit vectors and compared with $\alpha-\beta$ component of shunt HAPF currents. The error is fed to the PIcontroller, where its output represents the voltage required to push the current to the reference value.

To generate the above current, shunt HAPF requires a regulated d.c. bus voltage which is achieved using d.c. voltage controller implemented with PI-controller in d-q plane. The d.c. bus voltage is compared with the reference value and fed to the PI-controller. It can be noted that the angle between grid voltage and capacitive reactive current flowing through the passive filter is always less than $90^{\circ}$, because of the presence of resistances of $L_{f}$ and $C_{f}$. In actual condition, the capacitor current is decided by the difference between the grid voltage and the converter output a.c. voltage. The angle of this current, which decides the active power flow, can be further controlled by controlling the a.c. voltage of the converter which is aligned along q-axis, whereas the grid voltage is aligned along d-axis. Hence the active power drawn by the converter, which is responsible for charging the d.c. capacitor, can be controlled by controlling the converter a.c. output voltage which is aligned along q-axis. Hence PI-controller output will be a q-axis quantity while keeping d-axis quantity to zero. The output of PI-controller is then transformed to $\alpha-\beta$ plane and added with the output from the current controller to get the total modulating signal. The resulting $\alpha-\beta$ modulating signal is then transformed to three-phase plane. The complete block diagram of the control algorithm is shown in figure 2 . Space vector modulation technique is used for generating the PWM pulses. The whole control algorithm is implemented on a digital signal processor, TMS320F2812, based controller. The PIcontroller constant for d.c. voltage controller and current controller is derived in the following sections. 


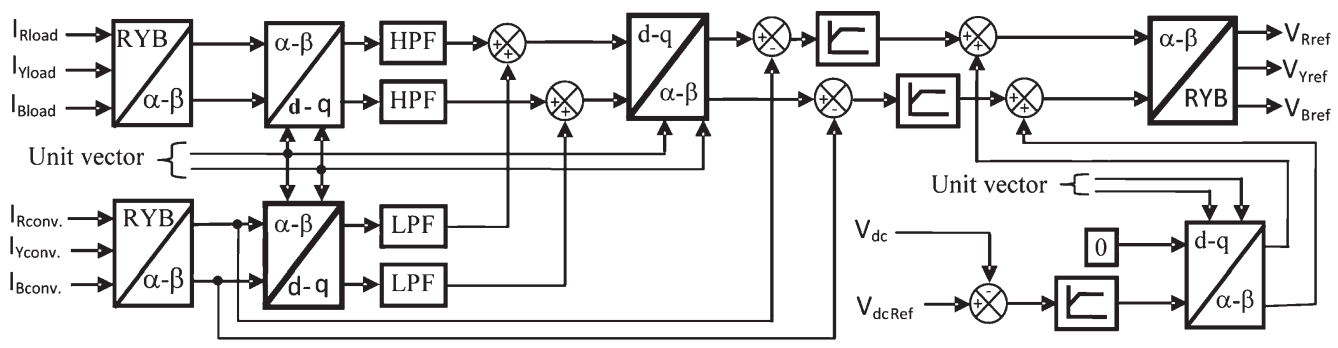

Figure 2. Block diagram of control strategy.

(a) Current controller PI-constants

Single phase equivalent circuit of shunt HAPF is shown in figure 3 , where $v_{\text {conv }}$ and $i_{\text {conv }}$ are its output voltage and current. Closed loop block diagram of shunt HAPF with current controller is shown in figure 4. Its closed loop step response is given by

$$
i_{\text {conv }}(t)=\frac{k_{I}}{L_{f}} \frac{1}{\left(a^{2}+b^{2}\right)}+\frac{k_{P}}{b L_{f}} e^{a t} K \sin (b t-\phi)
$$

where

$$
\begin{aligned}
& K=\sqrt{\frac{\left(k_{I} / k_{P}\right)^{2}+2 a\left(k_{I} / k_{P}\right)+\left(a^{2}+b^{2}\right)}{\left(a^{2}+b^{2}\right)}} \\
& \tan \phi=\frac{b k_{I}}{k_{P}\left(a^{2}+b^{2}\right)+k_{I} a}, \\
& a=-\left(\frac{R_{f}+k_{P}}{2 L_{f}}\right) \text { and } \\
& b=\sqrt{\left(\frac{R_{f}+k_{P}}{2 L_{f}}\right)^{2}-\left(\frac{1+C_{f} k_{I}}{L_{f} C_{f}}\right)}
\end{aligned}
$$

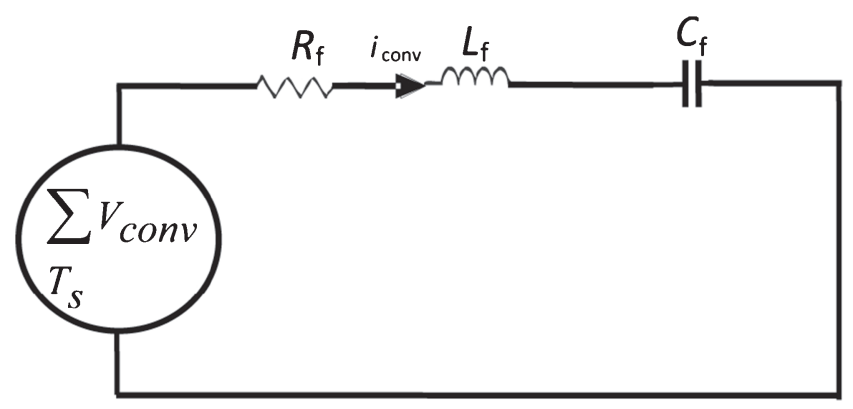

Figure 3. Single phase equivalent circuit of Shunt HAPF. 


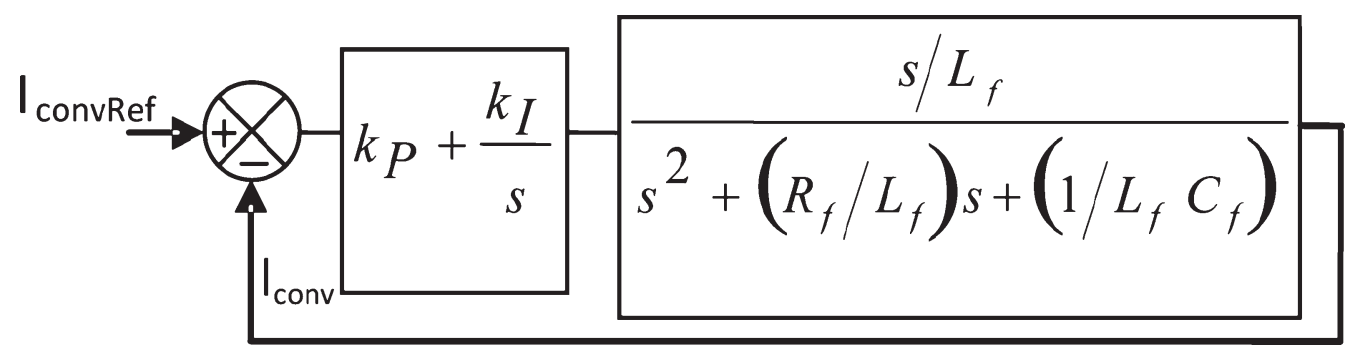

Figure 4. Block diagram of Shunt HAPF current.

The transient part settles in one current controller time constant $\left(\tau_{\mathrm{i}}\right)$ if 'at' equals to -1 at $t=\tau_{i}$. Using (16), $k_{P}$ can be solved as,

$$
k_{P}=\left(\frac{2 L_{f}}{\tau_{i}}\right)-R_{f}
$$

Using block diagram given in figure 4, the zero of the transfer function is given by, $k_{I} / k_{P}$. Dynamic characteristic can be improved by pushing zero far from real part of the complex pole ('n' times), given by

$$
\frac{k_{I}}{k_{P}}=-n a
$$

The closed loop step response to various values of ' $n$ ' is given in figure 5 .

For $\mathrm{n} \neq 0$, step response is having a steady state d.c. value, which implies that if a d.c. quantity appears in the current reference or in the feedback due to ADC offset, sensor offset, etc., the shunt HAPF current will have a d.c. quantity, which eventually charge the a.c. filter capacitor, which is to be avoided. Hence it is desirable to keep the value of $\mathrm{n}=0$, which implies the integral constant, $\mathrm{k}_{\mathrm{I}}$, is zero. The sampling frequency and the switching frequency are the same value and the value is fixed as $10 \mathrm{kHz}$, to suit the harmonic spectrum. $\tau_{\mathrm{i}}$ value shall be selected more than this period to avoid oscillations. Hence $\tau_{\mathrm{i}}$ is selected as $120 \mu \mathrm{s}$.

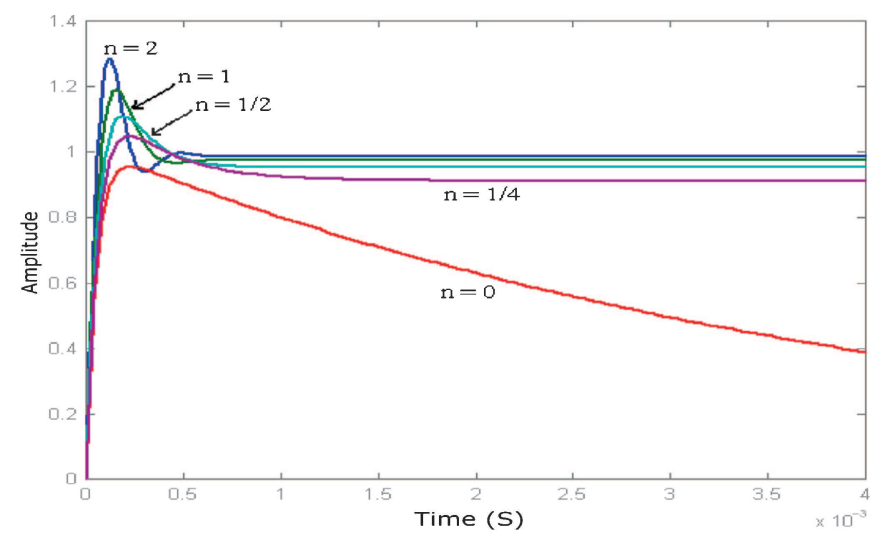

Figure 5. Variation of step response for different values of ' $n$ '. 
(b) d.c. Bus controller PI-constants

It can be assumed that the rate at which inductor current varies is one order higher than the rate at which capacitor voltage varies. Therefore, the controller for capacitor voltage and inductor current can be decoupled. Hence, the variation of d.c. capacitor voltage can be assumed as a first order equation, and is given by,

$$
\tau_{v} \frac{d v_{d c}}{d t}+v_{d c}=V_{d c \operatorname{Ref}}
$$

where $v_{d c}$ is the d.c. bus voltage, $V_{d c \text { Ref }}$ is the d.c. bus voltage reference and $\tau_{v}$ is the time constant chosen for the d.c. bus controller.

The lowest order of d.c. bus ripple is $300 \mathrm{~Hz}$. Hence, $\tau_{v}$ is selected one order higher than its period and fixed as $30 \mathrm{~ms}$. This will eliminate the effect of d.c. bus ripple in the controller output. If $C_{d c}$ is the capacitance of d.c. bus, then voltage equation for the d.c. bus is given by,

$$
C_{d c} \frac{d v_{d c}}{d t}=i_{d c}
$$

where $\mathrm{i}_{d c}$ is the current flowing into the capacitor.

Since converter to grid direction of current is taken as positive and controller output is the q-axis quantity, $i_{d c}$ should be positive in (20). Combining (19) and (20),

$$
i_{d c}=k_{p v d c}\left(V_{d c \operatorname{Ref}}-v_{d c}\right)
$$

where $k_{p v d c}=C_{d c} / \tau_{v}$ is the proportional constant of the d.c. bus controller.

The $\mathrm{k}_{\mathrm{I}}$ of the PI-controller is designed based on the ESR of the capacitor. Using power balance equation between a.c. and d.c. variable, the relation between fundamental peak value of shunt HAPF output voltage in $\alpha-\beta$ plane and the d.c. current can be derived as,

$$
v_{\operatorname{conv}(\alpha-\beta) p k}=\frac{(3 / 2) V_{d c \operatorname{Ref}}}{i_{\operatorname{conv}(\alpha-\beta) p k}} \times i_{d c}
$$

where $i_{\operatorname{conv}(\alpha \beta) p k}$ is the peak value of fundamental component of shunt HAPF current in $\alpha-\beta$ plane, which is fixed by passive filter value. $v_{\operatorname{con} v(\alpha \beta) p k}$ represents the q-axis quantity of d.c. bus PI-controller while d-axis quantity is set to zero as shown in figure 2. While implementing, the multiplication factor in (22) is combined with the actual value $k_{p v d c}$ given in (21).

\section{The hardware configuration}

The schematic of the test circuit is shown in figure 1. Three-phase diode bridge rectifier of $150 \mathrm{~A}$ rating is built using SanRex diode DD240KB160 which is used as the polluting load. The rectifier d.c. side capacitor, $\mathrm{C}$, is $9400 \mu \mathrm{F}(4700 \mu \mathrm{F}, 450 \mathrm{~V}$ two in series of four parallel circuits) and the resistor, $\mathrm{R}$, is $7 \Omega$. After pre-charging the d.c. capacitor, load is connected to the grid of $415 \mathrm{~V}$ line to line r.m.s, $50 \mathrm{~Hz}$, as shown in figure 1. The source inductance, $\mathrm{L}_{\mathrm{s}}$, of the grid is $53.6 \mu \mathrm{H}$. Three phase shunt HAPF of $50 \mathrm{kVA}, 415 \mathrm{~V}$ input, $50 \mathrm{~Hz}$ is built using IGBTs. The d.c. bus voltage of shunt HAPF is set to $300 \mathrm{~V}$ and its peak to peak ripple is chosen as $2 \%$ of rated voltage. The selection of the IGBT is based on various parameters described below: 


\subsection{Switching frequency $\left(f_{s}\right)$}

Minimum value of $f_{s}$ is decided by the highest order harmonics intended to compensate by shunt HAPF, which is $650 \mathrm{~Hz}$. Hence $f_{s}$ should be one order higher than $650 \mathrm{~Hz}$, and here $f_{s}$ chosen as $10 \mathrm{kHz}$. Hence IGBT should be able operate at this frequency.

\subsection{Voltage and current rating}

IGBT voltage rating should be higher than the selected d.c. voltage of $300 \mathrm{~V}$. By considering the voltage spike of $50 \%$ of rated value due to parasitic inductance between the d.c. capacitor and IGBT, the minimum voltage required is $450 \mathrm{~V}$. The peak current rating of shunt HAPF is 100A. Choosing an overload capacity of $20 \%$ of rated value, minimum current rating required for IGBT is $120 \mathrm{~A}$. Also, it is found that, by taking the thermal design in consideration, optimal design can be obtained by choosing the IGBT current rating as twice the required rated current. Hence 200A IGBT from Mitsubishi, CM200DU12NFH, is selected.

All three phase legs of the converter modules are placed in the same heatsink. The fan is placed in such a way that the airflow is vertical to the heatsink base for the shorter air length. In order to minimize the stray inductance of the converter stack sandwiched bus bar architecture is used. Substituting the above detailed parameters in the equations derived in Section 2, the major components of shunt HAPF are designed and the values are given in table 1 . The full hardware setup is shown in figure 6. The digital controller for this system is built around Texas Instrument DSP TMS320F2812. The digital controller has simultaneous sampling, 12 bit ADC with a maximum conversion time of $6.6 \mu \mathrm{s}$. PWMs are generated with a dead-time of $2.4 \mu \mathrm{s}$.

\section{Practical considerations}

\subsection{Operation when more loads are added}

SHAPF is a current controlled active filter. As explained in Section 3: Control Algorithm, the reference to the current controller is derived from the sensed load current. And SHAPF is constrained to sink or source only the current which follows the reference fed to the current controller. Hence, if new load is added to the grid and if the load connection is such that the current sensed by the current sensor includes the additional load, SHAPF will continue to compensate for the harmonics content in the net load, within the capacity of the installed SHAPF. If the total harmonics demand exceeds the capacity of the installed SHAPF, it will supply the harmonics to the grid limited by its current rating. The PI-constants remain same since it is independent of load currents and normally PI-constant would be designed for maximum bandwidth. If the new load is connected in such a way that the additional load current is not sensed by the current sensor, then SHAPF will not source/sink the additional harmonics current to the grid. Even from the sensed load current, we can choose a particular harmonic to be compensated as current controller reference. In such case only that particular harmonics will be compensated; however, this is not addressed in detail because it is outside the scope of the paper.

Table 1. Major components of shunt HAPF.

\begin{tabular}{llll}
\hline $\mathrm{L}_{\mathrm{f}}=1.5 \mathrm{mH}$ & $\mathrm{C}_{\mathrm{f}}=140 \mu \mathrm{F}$ & $\mathrm{C}_{\mathrm{dc}}=8200 \mu \mathrm{F}$ & $\mathrm{I}_{\mathrm{c}(\mathrm{rms})}=35 \mathrm{~A}$ \\
\hline
\end{tabular}




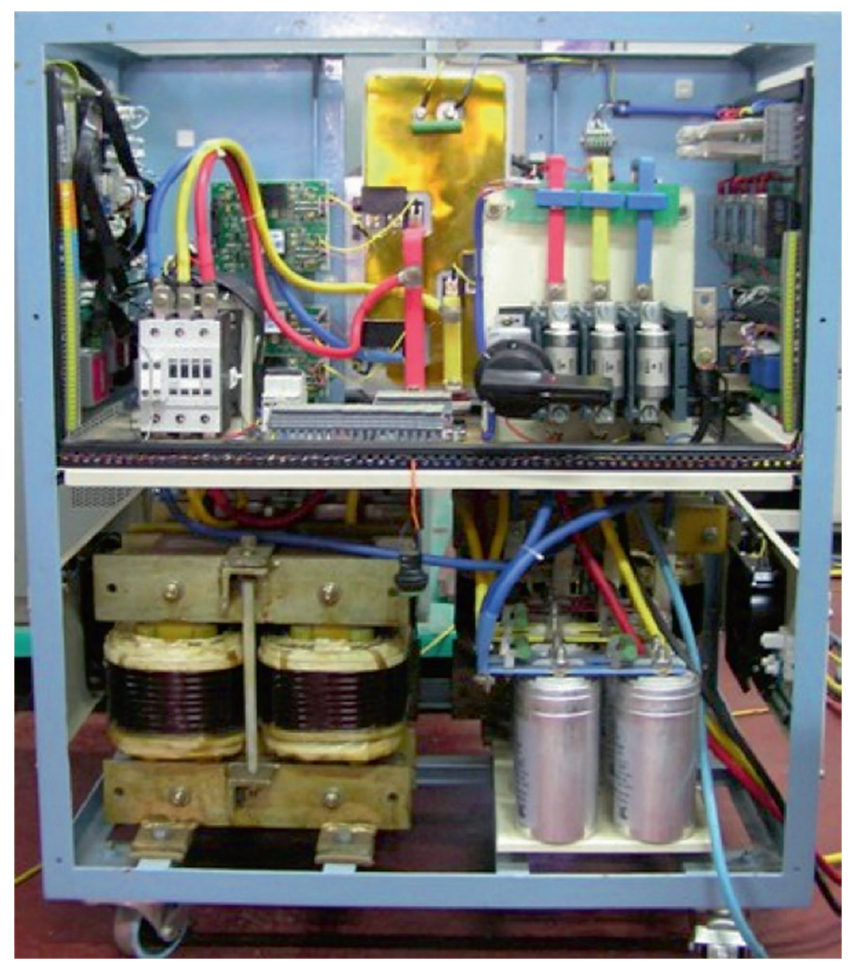

Figure 6. Shunt HAPF assembled in a panel.

Since SHAPF works based on current controller and its bandwidth is much higher than the low order harmonics that may exist in the grid, the chance of parallel resonance due to newly introduced load is remote.

\subsection{Protections}

Protections are provided against excessive increase of four parameters; grid voltage, SHAPF current, d.c. voltage and temperature. Software as well as hardware protections are given for the above four parameters. Various practical cases can be considered for which protections are required for the above parameters. Since SHAPF is operating as a boost rectifier, d.c. voltage can go to higher than the nominal value if controller fails to regulate. In such case, by using hardware protection (which is nothing but a comparator which compares the sensed value) as well as software protection, the pulses are blocked and SHAPF is isolated from grid by opening the contactor. Similarly, due to any reason, if resonance occurs in the system, the SHAPF current exceeding the nominal value is prevented by hardware protection as well as software protection.

\section{Results}

Shunt HAPF is tested in the laboratory to validate the performance of both hardware and control strategy. Figure 7 shows that most of the grid voltage is dropped across the capacitor, $C_{f}$, and the resulting capacitive reactive current is also shown. Voltage T.H.D. is measured with 1 decimal 


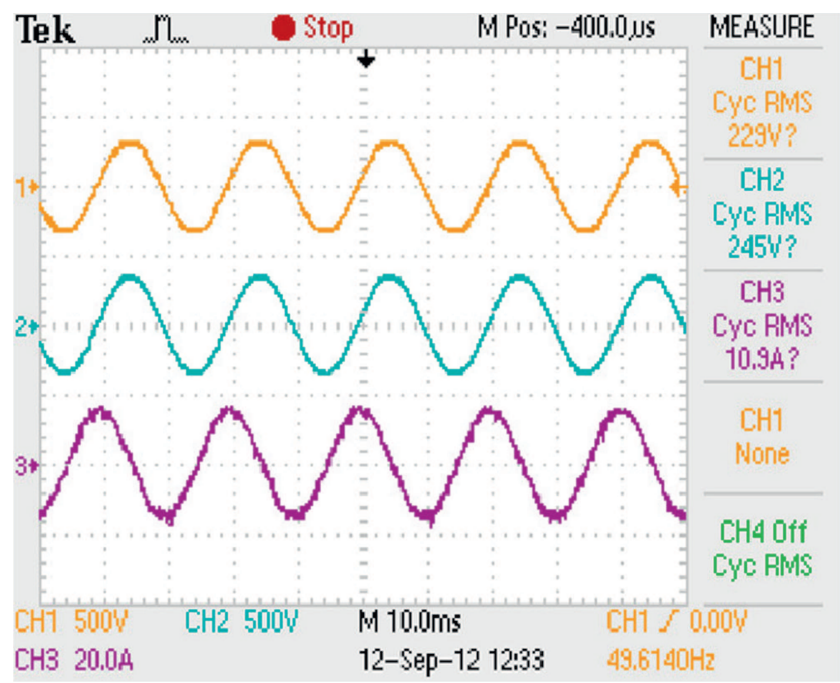

Figure 7. Grid voltage (CH1), a.c. Capacitor voltage $(\mathrm{CH} 2)$ and current $(\mathrm{CH} 3)$.

and current T.H.D is measured with 2 decimals accuracy. Table 2 gives individual harmonics in the grid current when (1) filters are not connected (2) only passive filter is connected (3) APF along with transformer is connected (4) shunt HAPF is connected.

It was observed that the reduction in harmonics with passive filter alone is not significant due to its inherent drawback. Due to the tolerance of LC component, where value of $L_{f}$ is $1.59 \mathrm{mH}$ and $C_{f}$ is $143.8 \mu \mathrm{F}$, the actual tuned frequency is $332.8 \mathrm{~Hz}$ instead of designed $350 \mathrm{~Hz}$. Also the 7 th order grid frequency is found to be $347 \mathrm{~Hz}$ during the test condition. Due to the variation in tuned frequency the impedance offered at $7^{\text {th }}$ harmonic by LC filter is $0.28 \Omega$, whereas grid impedance is $0.11 \Omega$. Hence major $7^{\text {th }}$ order harmonics take the path of grid rather than passive filter. When shunt HAPF is connected, since its operation does not depend on variation in tuned frequency, the reduction in harmonics is found to be appreciable. Figure 8 shows the source current waveform before and after compensation. From table 2, another comparison is between the SHAPF and the APF, which clearly shows drastic reduction of $5^{\text {th }}$ and $7^{\text {th }}$ harmonics due to the presence of PPF in the SHAPF.

For the purpose of cost comparison, considering use of the same coupling inductor of the APF in the PPF of the SHAPF, it can be seen that there is a cost reduction of $18 \%$ in SHAPF compared to APF.

Table 2. Grid current harmonics as $\%$ of full load fundamental.

\begin{tabular}{lcccc}
\hline & Without any filter & With passive filter & With APF & With shunt HAPF \\
\hline Fundamental & 100.0 & 100.0 & 100.0 & 100.0 \\
Harmonic 5 & 32.3 & 29.2 & 6.2 & 1.7 \\
Harmonic 7 & 15.2 & 12.5 & 3.5 & 1.6 \\
Harmonic 11 & 7.6 & 6.9 & 3.3 & 3.1 \\
Harmonic 13 & 5.2 & 4.9 & 2.3 & 1.9 \\
Total (I THD) & 37.8 & 33.8 & 10.1 & 9.3 \\
\hline
\end{tabular}




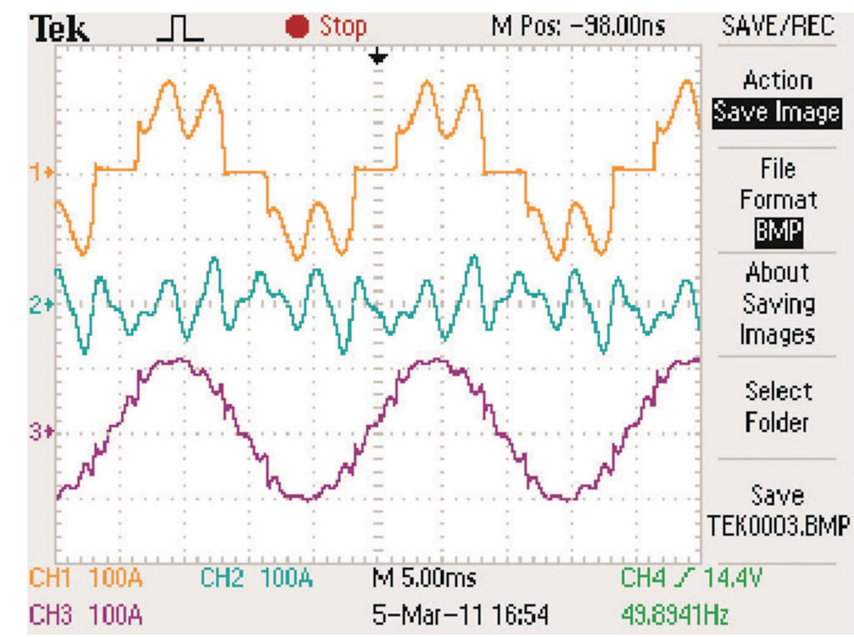

Figure 8. Un-compensated load current $(\mathrm{CH} 1)$, Compensated grid currents $(\mathrm{CH} 3)$ and Shunt HAPF current $(\mathrm{CH} 2)$.

Table 3. R.M.S. grid voltages and currents with their fundamental.

\begin{tabular}{lccc}
\hline & Without any filter & With passive filter & With shunt HAPF \\
\hline $\mathrm{V}_{\mathrm{RY}}, \mathrm{V}_{\mathrm{RY} 1}$ (in V) & $426.5,426.4$ & $403.4,403.2$ & $407.6,407.4$ \\
$\mathrm{I}_{\mathrm{R}}, \mathrm{I}_{\mathrm{R} 1}$ (in A) & $81.39,76.00$ & $84.37,79.90$ & $81.39,80.99$ \\
$\mathrm{~V}_{\mathrm{YB}}, \mathrm{V}_{\mathrm{YB} 1}$ (in V) & $409.9,409.7$ & $401.5,401.4$ & $406.2,406.1$ \\
$\mathrm{I}_{\mathrm{Y}}, \mathrm{I}_{\mathrm{Y} 1}$ (in A) & $77.40,71.65$ & $77.57,72.43$ & $75.26,74.75$ \\
$\mathrm{~V}_{\mathrm{BR}}, \mathrm{V}_{\mathrm{BR} 1}$ (in V) & $406.2,406.0$ & $409.6,409.5$ & $406.6,406.5$ \\
$\mathrm{I}_{\mathrm{B}}, \mathrm{I}_{\mathrm{B} 1}$ (in A) & $73.90,68.26$ & $78.17,73.00$ & $74.66,74.12$ \\
\hline
\end{tabular}

Table 4. Summary of various quantities defined as per - IEEE1459 standard.

\begin{tabular}{lccc}
\hline & Without filter & With passive filter & With shunt HAPF \\
\hline $\mathrm{V}_{\mathrm{e}}, \mathrm{I}_{\mathrm{e}}$ & $239.2 \mathrm{~V}, 77.6 \mathrm{~A}$ & $233.7 \mathrm{~V}, 80.1 \mathrm{~A}$ & $234.9 \mathrm{~V}, 77.2 \mathrm{~A}$ \\
$\mathrm{~V}_{\mathrm{e} 1}, \mathrm{I}_{\mathrm{e} 1}$ & $239.1 \mathrm{~V}, 72.0 \mathrm{~A}$ & $233.6 \mathrm{~V}, 75.2 \mathrm{~A}$ & $234.8 \mathrm{~V}, 76.6 \mathrm{~A}$ \\
$\mathrm{THD}_{\mathrm{eI}}$ & 0.4011 & 0.3670 & 0.1120 \\
$\mathrm{THD}_{\mathrm{eV}}$ & 0.0279 & 0.0262 & 0.0256 \\
$\mathrm{D}_{\mathrm{eI}}$ & 20726.30 & 19342.58 & 6049.46 \\
$\mathrm{D}_{\mathrm{eV}}$ & 1441.18 & 1379.28 & 1380.72 \\
$\mathrm{~S}_{\mathrm{eH}}$ & 578.06 & 506.20 & 154.64 \\
$\mathrm{~S}_{\mathrm{eN}}$ & 20784.39 & 19398.30 & 6206.96 \\
Harmonic pollution & 0.4022 & 0.3681 & 0.1149 \\
\hline
\end{tabular}

Table 3 lists the measured r.m.s. grid line to line voltages, currents and their fundamental components (suffix by 1 ) in $\mathrm{R}, \mathrm{Y}$ and $\mathrm{B}$ phases. Using table 3 effective voltage $\left(\mathrm{V}_{\mathrm{e}}\right)$, fundamental effective voltage $\left(V_{e 1}\right)$, effective current $\left(I_{e}\right)$ and fundamental effective current $\left(I_{e 1}\right)$ are computed as per IEEE 1459 standard and are listed in table 4 . Table 4 also gives various computed powers, current distortion power $\left(\mathrm{D}_{\mathrm{eI}}\right)$, voltage distortion power $\left(\mathrm{D}_{\mathrm{eV}}\right)$, harmonic apparent power $\left(\mathrm{S}_{\mathrm{eH}}\right)$, non-fundamental apparent power $\left(\mathrm{S}_{\mathrm{eN}}\right)$. Equivalent total harmonic distortion of voltage 
$\left(\mathrm{THD}_{\mathrm{eV}}\right)$ and current $\left(\mathrm{THD}_{\mathrm{eI}}\right)$ are given in table 4. Harmonic pollutions in various cases are calculated from the computed powers. Comparisons of harmonic pollution in various cases are given in table 4. It is found that using shunt HAPF the harmonic pollution is brought down to 0.1160 from 0.4022 .

\section{Conclusion}

In this paper a practical design criteria for a transformer-less three phase shunt hybrid active power filter is explained. A control strategy is derived with special attention to the integration of series passive filter. Theoretical analysis based on transfer function is carried out to design the d.c. voltage and current controller with a proportional-plus-integral (PI) regulator. The effectiveness of the design and control method is verified using results from the laboratory prototype.

\section{References}

Akagi H, Srianthumrong S and Tamai Y 2003 Comparisons in circuit configuration and filtering performance between hybrid and pure shunt active filters. Proc. Conf. Rec. IAS Annual Meeting 2: 11951202

Akagi H 1996 New trends in active filters for power conditioning. IEEE Trans. Ind. Appl. 32(6): 1312-1322

Akagi H, Nabae A and Atoh S 1986 Control strategy of active power filters using multiple voltage-source PWM converters. IEEE Trans. Ind. Appl. 22(3): 460-465

Avik Bhattacharya and Chandan Chakraborty 2011 A shunt active power filter with enhanced performance using ANN-based predictive and adaptive controllers. IEEE Trans. Ind. Electron. 58(2): 421-428

Bhattacharya S, Divan D M and Cheng P T 1997 Hybrid Solutions for Improving Passive Filter Performance in High Power Applications. IEEE Trans. Ind. Appl. 33(3): 732-747

Bhattacharya S, Divan D M and Banerjee B 1991 Synchronous frame harmonics isolator using active series filter. Proc. EPE: 3.030-3.035

Das J C 2004 Passive filters-Potentialities and limitations. IEEE Trans. Ind. Appl. 40(1): 232-241

Fujita H and Akagi H 1991 A practical approach to harmonic compensation in power systems-Series connection of passive and active filters. IEEE Trans. Ind. Appl. 27(6): 1020-1025

Herrera R S, Salmern P and Kim H 2008 Instantaneous reactive power theory applied to active power filter compensation: different approaches, assessment, and experimental results. IEEE Trans. Ind. Electron. 55(1): 184-196

Hussein Kazem A 2013 Harmonic mitigation techniques applied to power distribution networks. Advances in power electronics, Hindawi Publishing Corporation 2013 Article ID 591680, 10 pages doi: $10.1155 / 2013 / 591680$

Inzunza R and Akagi H 2005 A 6.6-kV transformerless shunt hybrid active filter for installation on a power distribution system. IEEE Trans. Power Electron. 20(4): 893-900

Komatsu Y and Kawabata T 1997 Experimental comparison of $p q$ and extension $p q$ method for active power filter. Proc. EPE: 2.729-2.734

Makram E B, Subramaniam E V, Girgis A A and Catoe R 1993 Harmonic filter design using actual recorded data. IEEE Trans. Ind. Appl. 29(6): 1176-1183

Peng F Z 1998 Application issues of active power filters. IEEE Ind. Appl. Mag. 4: 21-30

Peng F Z, Akagi H and Nabae A 1993 Compensation characteristics of the combined system of shunt passive and series active filters. IEEE Trans. Ind. Appl. 29(1): 144-152

Rastogi M, Mohan N and Edris A A 1995 Hybrid-active filtering of the harmonic currents in power systems. IEEE Trans. Power Delivery 10(4): 1994-2000 
Soares V, Verdelho P and Marques G D 1997 Active power filter control circuit based on the instantaneous active and reactive current id-iq method. Proc. IEEE Power Electronics Specialists Conference PESC 2: 1096-1101

Subhash Joshi T G, Aby Joseph and Gautam Poddar 2003 Active power factor correction for highly fluctuating industrial load. Proc. National Power Electronics Conference, India: 55-59

Uyyuru K R, Mishra M K and Ghosh A 2009 An optimization-based algorithm for shunt active filter under distorted supply voltages. IEEE Trans. Power Electron. 24(5): 1223-1232

Wu C J, Chiang J C, Yen S S, Liao C J, Yang J S and Guo T Y 1998 Investigation and mitigation of harmonic amplification problems caused by single-tuned filters. IEEE Trans. Power Delivery 13(3): 800-806 